\title{
Plasma Free Protein S Is Correlated with Disease Activity, but not with Subclinical Atherosclerosis among Patients with Systemic Lupus Erythematosus: A Cross-Sectional Study
}

\author{
Ju-Yang Jung, ${ }^{1}$ Sang Won Lee, ${ }^{1}$ Hyoun-Ah Kim ${ }^{1}$ and Chang-Hee Suh ${ }^{1}$ \\ ${ }^{1}$ Department of Rheumatology, Ajou University School of Medicine, Suwon, Gyeonggi-do, Republic of Korea
}

\begin{abstract}
A defect in clearance of apoptotic materials is pivotal in the pathogenesis of systemic lupus erythematosus (SLE). Protein S participates in the removal of apoptotic remnants and the anticoagulation pathway. The aim of the study was to clarify the relationship between plasma levels of free protein $S$ and the disease activity or subclinical atherosclerosis in SLE. Free protein $S$ was measured by an enzyme-linked immunosorbent assay, and patients were classified into two groups of free protein S levels: low $(<50 \%)$ and normal $(\geq 50 \%)$. One hundred-eleven Korean female patients with SLE were enrolled, and the levels of free protein $S$ were $67.4 \pm 19.7 \%$. Carotid plaque was detected in $25(22.5 \%)$ patients. Twenty-one patients with low free protein $S$ had lower hemoglobin (11.4 \pm 1.4 vs. $12.5 \pm 1.4 \mathrm{~g} / \mathrm{dL}$ ) and lymphocytes $(1,221 \pm 609$ vs. $1,720 \pm 1,097 / \mu \mathrm{L})$, higher erythrocyte sedimentation rate $(30.1 \pm 20.6$ vs. $20.8 \pm 17.8 \mathrm{~mm} /$ h), and lower complement $3(80.8 \pm 27.6$ vs. $103.4 \pm 25.8 \mathrm{mg} / \mathrm{dL})$ and complement 4 (15.6 \pm 10.4 vs. $21.5 \pm$ $7.6 \mathrm{mg} / \mathrm{dL}$ ) than those with normal protein $\mathrm{S}$. There was no significant difference in the proportion of patients with increased carotid artery intima-media thickness $(>4.6 \mathrm{~mm})$ or with carotid artery plaque between two groups. The low levels of free protein $S$ were associated with hemoglobin $(\mathrm{OR}=0.64, p=$ $0.04)$ and complement $3(\mathrm{OR}=0.96, p=0.005)$. Free protein $S$ is correlated with disease activity, but not with subclinical atherosclerosis in SLE.
\end{abstract}

Keywords: atherosclerosis; complement; hemoglobin; protein S; systemic lupus erythematosus

Tohoku J. Exp. Med., 2019 September, 249 (1), 1-7. (C) 2019 Tohoku University Medical Press

\section{Introduction}

Systemic lupus erythematosus (SLE) is a chronic inflammatory disease derived from the activated immune response, and one of the distinguishing features in its pathophysiology is the impaired clearance of apoptotic cells (Munoz et al. 2008). Delayed or incomplete clearance of apoptotic debris enables recurrent exposures of superfluous self-antigen to immune cells. Hyperactive immune cells, including macrophages and lymphocytes, damage tissues and release pro-inflammatory molecules, leading to inflammation. Tyro3, Axl, and Mer (TAM) receptors, and their ligands, protein $\mathrm{S}$ and growth arrest-specific protein 6 (Gas6), are known to be required for the optimal phagocytosis of apoptotic cells (Rothlin and Lemke 2010; van der Meer et al. 2014). Alteration of such receptors and ligands has been found in patients with SLE and is considered to contribute to prolonged auto-antigen production and repeated immune response provocations (Suh et al. 2010; Wu et al. 2011; Gheita et al. 2012; Zizzo et al. 2013; Wu et al. 2014; Zhu et al. 2014).

Protein $\mathrm{S}$ is not only a ligand of TAM receptors, but also an anticoagulant cofactor for activated protein C (APC) (Suleiman et al. 2013). In the coagulation pathway, APC inactivates coagulation factors Va and VIIIa. Deficient levels of protein S limit the action of APC, increasing susceptibility to coagulation or thrombosis. It is well known that protein $\mathrm{S}$ deficiency results in a hypercoagulable status, leading to arterial and venous thrombosis or vasculopathy (Engesser et al. 1987; Pintao et al. 2013). Protein S is produced in various cells, including liver cells, endothelial cells, and monocyte-derived cells. Plasma protein S levels vary according to age, sex, hormonal status, lipid metabolism and genetic factors (Marlar and Gausman 2011). Of the protein $\mathrm{S}$ found in plasma, $60 \%$ is bound to $\mathrm{C} 4 \mathrm{~b}$-binding protein (C4BP), with the remaining $40 \%$ found in free form. The action of the C4BP-protein $\mathrm{S}$ complex is weaker than free form of protein S. Protein $\mathrm{S}$ acts as a ligand for TAM receptors, involving a removal of apoptotic debris. It has been revealed that an alteration of Gas6/Protein S-TAM system renders defects in clearance of apoptotic debris, affecting homeostasis and inflammation (van der Meer et al. 2014; Tabib et al. 2018). In addition to its anti-thrombotic activity, protein $\mathrm{S}$ binds to phosphatidylserine exposed on

Received May 23, 2019; revised and accepted August 15, 2019. Published online September 10, 2019; doi: 10.1620/tjem.249.1.

Correspondence: Chang-Hee Suh, M.D., Ph.D., Department of Rheumatology, Ajou University School of Medicine, 164 Worldcup-ro,

Yeoungtong-gu, Suwon, Gyeonggi-do 16499, Republic of Korea.

e-mail: chsuh@ajou.ac.kr 
the surface of apoptotic cells and stimulates macrophage phagocytosis (Anderson et al. 2003). Although protein S deficient mice exhibited defect in their vascular development and generated elevated levels of thrombin, these findings are consistent with the data for human subjects (Levine et al. 2014). In systemic inflammatory status including sepsis, the decreased levels of protein $\mathrm{S}$ and $\mathrm{C}$ have been regarded as biomarkers for severity and defects in physiologic inhibition of coagulation (El Beshlawy et al. 2010; Mihajlovic et al. 2017). In SLE, free protein S levels are decreased compared to healthy controls, and this decrease is correlated with complement levels or disease activity markers (Suh et al. 2010; Recarte-Pelz et al. 2013).

Plasma free protein $\mathrm{S}$ levels have been rarely studied in patients with SLE, and the relationship between free protein $\mathrm{S}$ and the propensity to develop atherosclerosis in SLE has not been clarified. We investigated the levels of free protein S in patients with SLE and aimed to clarify the relationship of the levels of free protein S with subclinical atherosclerosis or lupus disease activity markers.

\section{Methods}

\section{Study participants}

Only female patients with SLE were recruited. All patients met the Systemic Lupus International Collaborating Clinics (SLICC) classification criteria for SLE (Petri et al. 2012), and received standardof-care treatment for SLE. Any patients with cardiovascular disease, cancer, chronic renal failure, or pregnancy were excluded. Traditional risk factors were assessed by chart review or by participant interviews. A family history risk factor was defined as 'having someone with premature cardiovascular disease before 55 years of age among first degree male relatives, or before 65 years of age among female relatives'. Smoking was defined as being present if the subject had smoked for more than 20 pack-years, despite cessation at the time of recruitment. The body mass index (BMI) and waist-hip ratio (WHR) were measured for all participants. Comprehensive medication histories were obtained, including the use of corticosteroids, immunosuppressants, anticoagulants, and statins.

\section{Laboratory test and disease activity assessment}

Routine chemical analyses, a complete blood count, the erythrocyte sedimentation rate (ESR), lipid profiles (total cholesterol, triglyceride, high density lipoprotein (HDL), and low density lipoprotein (LDL) cholesterol), and complement levels (C3 and C4) were examined for each patient. Additionally, autoantibody results were recorded, including antinuclear antibodies (ANA), anti-doublestranded DNA (anti-dsDNA) antibodies, anti-cardiolipin antibodies (ACA), and lupus anticoagulant (LA). Plasma levels of free protein S were assessed using an enzyme-linked immunosorbent assay (Corgenix Medical, CO, USA), which uses a monoclonal antibody specific for free protein $\mathrm{S}$, and the data are reported in percent (\%) of normal, relative to a reference plasma that has been standardized against Secondary Standard for Coagulation/International Society on Thrombosis and Haemostasis (SSC/ISTH) preparation, which is calibrated to World Health Organization (WHO) standards. The ranges of normal population were $50 \sim 150 \%$. Disease activity and diseaserelated damage were assessed using the Systemic Lupus Erythematosus Disease Activity Index (SLEDAI) and SLICC/American College of
Rheumatology (SLICC/ACR) Damage Index, respectively (Bombardier et al. 1992; Gladman et al. 1997).

\section{Measurement of carotid artery intima-media thickness and plaque}

Carotid artery intima-media thickness (cIMT) and presence of carotid artery plaque, which represent subclinical atherosclerosis were measured using an ultrasound machine $(11 \mathrm{MHz}$ linear transducer, LOGIQ P6 pro; GE, Fairfield, CT, USA). Using B-mode ultrasound, the right and left common carotid arteries were scanned longitudinally, and bifurcation of the carotid artery was checked. Then, the three portions were measured at $10 \mathrm{~mm}$ intervals from $10 \mathrm{~mm}$ upwards, and mean values were calculated. Values from each side were then averaged to produce an overall measurement of the cIMT (Naqvi and Lee 2014). The presence of carotid artery plaque was assessed. To minimize inter-observer related bias, each test was performed by one investigator who was kept blind to the clinical data.

\section{Ethics approval and consent to participate}

This study was approved by the Institutional Review Board of Ajou University Hospital (AJURB-MED-KSP-12-387), and all procedures involving human participants were conducted according to the principles expressed in the Declaration of Helsinki. Each participant provided written informed consent.

\section{Statistical analysis}

Data are expressed as mean \pm standard deviation for continuous variables or frequencies and percentages for categorical variables. The levels of free protein $\mathrm{S}$ were classified into two groups and clinical features were compared by using Spearman's rho method. The variables which showed a significant difference included the logistic regression analysis with univariate and multivariate ways. Two-sided $p$-values of less than 0.05 were considered statistically significant. All computations were performed using the SPSS version 22.0 (SPSS statistics IBM Corp. Armonk, NY, USA)

\section{Results \\ Clinical characteristics of patients}

Basic characteristics of the patients with SLE are shown in Table 1. A total of 111 of Korean female patients with SLE were enrolled. Disease duration was $76.3 \pm 52.1$ months. All patients had ANA, 34 patients (30.6\%) had anti-dsDNA antibodies, 27 patients (24.3\%) had ACA, and 12 patients $(10.8 \%)$ had LA. Forty-seven patients $(42.3 \%)$ had arthritis, 20 patients (18\%) had alopecia, and 19 patients $(14.4 \%)$ had renal involvement. SLEDAI value was $4.4 \pm 3.3$, and only three patients were given a score of 1 on the SLICC Damage Index. Of the patients enrolled, 106 patients $(95.5 \%)$ took hydroxychloroquine, $75(73.5 \%)$ took corticosteroids and 34 (30.6\%) took non-steroidal antiinflammatory drugs (NSAIDs). The current corticosteroid dose was $2.6 \pm 3.0 \mathrm{mg}$ prednisolone-equivalent, and the accumulated corticosteroid dose was $10.5 \pm 16.8 \mathrm{~g}$ prednisolone-equivalent. The level of free protein $\mathrm{S}$ was $67.4 \pm$ $19.7 \%$, cIMT was $4.06 \pm 0.85 \mathrm{~mm}$, and 25 patients $(22.5 \%)$ had carotid plaque.

Clinical features of patients with low plasma free protein $S$ In this study, the levels of free protein $\mathrm{S}$ were mea- 
Table 1. The clinical characteristics of patients with systemic lupus erythematosus.

\begin{tabular}{|c|c|}
\hline $\mathrm{n}$ & 111 \\
\hline Age, years & $38.9 \pm 7.7$ \\
\hline Disease duration, months & $76.3 \pm 52.1$ \\
\hline Smoking & $4(3.6)$ \\
\hline Hypertension & $4(3.6)$ \\
\hline Family history of CVD & $23(19.8)$ \\
\hline Menopause & $10(9.0)$ \\
\hline BMI, $\mathrm{kg} / \mathrm{m}^{2}$ & $21.1 \pm 2.8$ \\
\hline WHR & $0.81 \pm 0.06$ \\
\hline Hemoglobin, g/dL & $12.3 \pm 1.4$ \\
\hline $\mathrm{WBC}, / \mu \mathrm{L}$ & $5,536 \pm 2,066$ \\
\hline Lymphocyte, $/ \mu \mathrm{L}$ & $1,626 \pm 1,039$ \\
\hline Platelet, $\times 10^{3} / \mu \mathrm{L}$ & $217 \pm 66$ \\
\hline $\mathrm{ESR}, \mathrm{mm} / \mathrm{hr}$ & $22.3 \pm 18.4$ \\
\hline Total cholesterol, mg/dL & $160.4 \pm 37.4$ \\
\hline Triglyceride, $\mathrm{mg} / \mathrm{dL}$ & $101.0 \pm 72.9$ \\
\hline HDL cholesterol, mg/dL & $53.5 \pm 13.9$ \\
\hline LDL cholesterol, mg/dL & $86.7 \pm 30.6$ \\
\hline Complement 3, mg/dL & $99.15 \pm 26.5$ \\
\hline Complement $4, \mathrm{mg} / \mathrm{dL}$ & $20.3 \pm 8.6$ \\
\hline Anti-dsDNA Ab & $34(30.6)$ \\
\hline Anti-phospholipid Ab & $32(28.8)$ \\
\hline Anti-cardiolipin Ab & $27(24.3)$ \\
\hline Lupus anticoagulant & $12(10.8)$ \\
\hline Mucocutaneous involvement & $44(39.3)$ \\
\hline Arthritis & $47(42.3)$ \\
\hline Renal involvement & $19(14.4)$ \\
\hline SLEDAI & $4.4 \pm 3.3$ \\
\hline Free protein $\mathrm{S}, \%$ & $67.4 \pm 19.7$ \\
\hline Carotid IMT, mm & $4.06 \pm 0.85$ \\
\hline Carotid plaque & $25(22.5)$ \\
\hline
\end{tabular}

Data are shown as mean $\pm \mathrm{SD}$, or the number of patients $(\%$ of the patient number per each group).

CVD, cardiovascular disease; BMI, body mass index; WHR, waist-hip ratio; WBC, white blood cells; ESR, erythrocyte sedimentation rate; HDL, high density lipoprotein; LDL, low density lipoprotein; dsDNA, double-strand deoxyribonucleic acid; $\mathrm{Ab}$, antibody; SLEDAI, systemic lupus erythematosus disease activity index; IMT, intima-media thickness.

sured as a percentile, and it is stated that $50 \sim 150 \%$ is normal range as a reference (Kristoffersen et al. 2017). Twenty-one patients had low levels of plasma free protein $\mathrm{S}$ $(<50 \%)$ which means deficient level (Table 2). The patients with low level of free protein $\mathrm{S}$ had lower hemoglobin $(11.4 \pm 1.4$ vs. $12.5 \pm 1.4 \mathrm{~g} / \mathrm{dL}, p=0.003)$ and lymphocyte count $(1,221 \pm 609$ vs. $1,720 \pm 1,097 / \mu \mathrm{L}, p=$ $0.026)$, higher ESR ( $30.1 \pm 20.6$ vs. $20.8 \pm 17.8 \mathrm{~mm} / \mathrm{h}, p=$ $0.023)$, and lower complement $3(80.8 \pm 27.6$ vs. $103.4 \pm$
$25.8 \mathrm{mg} / \mathrm{dL}, p=0.001)$ and complement $4(15.6 \pm 10.4$ vs. $21.5 \pm 7.6 \mathrm{mg} / \mathrm{dL}, p=0.005)$ compared to those with normal levels of free protein S. There was no significant difference in the proportion of patients with increased cIMT $(>4.6 \mathrm{~mm})$ or carotid plaque between two groups.

Associations of the clinical features to low levels of plasma free protein $S$

On univariate regression analysis, the low levels of 
Table 2. The comparison of SLE patients according to the free protein S level.

\begin{tabular}{|c|c|c|c|}
\hline & Free protein $\mathrm{S} \geq 50 \%$ & Free protein $\mathrm{S}<50 \%$ & $p$ value \\
\hline $\mathrm{n}$ & 90 & 21 & \\
\hline Age, years & $39.4 \pm 8.1$ & $36.6 \pm 5.1$ & 0.12 \\
\hline Duration, months & $93.7 \pm 59.5$ & $72.3 \pm 49.8$ & 0.1 \\
\hline Hemoglobin, g/dL & $12.5 \pm 1.4$ & $11.4 \pm 1.4$ & $0.003^{*}$ \\
\hline Leukocyte, $/ \mu \mathrm{L}$ & $5,703 \pm 2,082$ & $4,823 \pm 1,879$ & 0.1 \\
\hline Lymphocyte, / $\mu \mathrm{L}$ & $1,720 \pm 1,097$ & $1,221 \pm 609$ & $0.03^{*}$ \\
\hline Platelet, $\times 10^{3} / \mu \mathrm{L}$ & $221 \pm 64$ & $203 \pm 70$ & 0.15 \\
\hline $\mathrm{ESR}, \mathrm{mm} / \mathrm{hr}$ & $20.8 \pm 17.8$ & $30.1 \pm 20.6$ & $0.02^{*}$ \\
\hline $\mathrm{CRP}, \mathrm{mg} / \mathrm{dL}$ & $0.16 \pm 0.35$ & $0.22 \pm 0.38$ & 0.62 \\
\hline T. cholesterol & $162.2 \pm 38.9$ & $152.8 \pm 29.7$ & 0.45 \\
\hline Triglyceride & $100.4 \pm 74.1$ & $103.6 \pm 69.2$ & 0.52 \\
\hline HDL cholesterol & $53.7 \pm 12.7$ & $52.8 \pm 18.4$ & 0.68 \\
\hline LDL cholesterol & $88.4 \pm 32.7$ & $79.3 \pm 18.1$ & 0.36 \\
\hline Complement $3, \mathrm{mg} / \mathrm{dL}$ & $103.4 \pm 25.8$ & $80.8 \pm 27.6$ & $0.001^{*}$ \\
\hline Complement $4, \mathrm{mg} / \mathrm{dL}$ & $21.5 \pm 7.6$ & $15.6 \pm 10.4$ & $0.005^{*}$ \\
\hline Anti-dsDNA Ab & $26(28.9)$ & $8(38)$ & 0.47 \\
\hline Anticardiolipin $\mathrm{Ab}$ & $24(26.6)$ & $3(14.2)$ & 0.24 \\
\hline Lupus anticoagulant & $11(12.2)$ & $1(4.7)$ & 0.32 \\
\hline Mucocutaneous involvement & $38(42.2)$ & $6(28.6)$ & 0.25 \\
\hline Arthritis & $40(44.4)$ & $7(33.3)$ & 0.36 \\
\hline Renal involvement & $15(14.4)$ & $4(14.2)$ & 0.8 \\
\hline SLEDAI & $4.3 \pm 3.0$ & $5.1 \pm 3.6$ & 0.33 \\
\hline \multicolumn{4}{|l|}{ Medication } \\
\hline Hydroxychloroquine & $86(95.6)$ & $20(95.2)$ & 0.95 \\
\hline NSAID & $31(34.4)$ & $3(14.2)$ & 0.07 \\
\hline Aspirin & $13(14.4)$ & $3(14.2)$ & 0.99 \\
\hline Statin & $4(4.4)$ & $1(4.7)$ & 0.37 \\
\hline Azathioprine & $5(5.6)$ & $5(23.8)$ & 0.08 \\
\hline Cyclophosphamide & $5(5.6)$ & $2(9.5)$ & 0.51 \\
\hline MMF & $8(8.9)$ & $1(4.7)$ & 0.54 \\
\hline Steroid current dose, $\mathrm{mg} / \mathrm{d}$ & $2.5 \pm 1.8$ & $2.5 \pm 1.4$ & 0.84 \\
\hline Steroid cumulative dose, $\mathrm{g}$ & $8.6 \pm 10.1$ & $18.9 \pm 3.1$ & 0.19 \\
\hline Carotid IMT > 4.6mm & $22(24.4)$ & $2(9.5)$ & 0.14 \\
\hline Carotid plaque & $20(22.2)$ & $5(23.8)$ & 0.88 \\
\hline
\end{tabular}

Data are shown as mean $\pm \mathrm{SD}$, or the number of patients $(\%$ of the patient number per each group).

SLE, systemic lupus erythematosus; ESR, erythrocyte sedimentation rate; dsDNA, double-strand deoxyribonucleic acid; Ab, antibody; SLEDAI, systemic lupus erythematosus disease activity index; NSAID, non-steroidal anti-inflammatory drugs; MMF, mycophenolate mofetil; IMT, intima media thickness.

${ }^{*} p<0.05$.

free protein $\mathrm{S}$ were associated hemoglobin levels (odds ratio $(\mathrm{OR})=0.6, p=0.003)$, lymphocyte $(\mathrm{OR}=1.0, p=$ $0.03)$, $\mathrm{ESR}(\mathrm{OR}=1.03, p=0.04), \mathrm{C} 3(\mathrm{OR}=0.96, p=$ $0.001)$ and $\mathrm{C} 4(\mathrm{OR}=0.91, p=0.007)$ (Table 3$)$. Then mul- tiple logistic analysis was performed to find associated factors for low levels of free protein $\mathrm{S}$ in patients with SLE. Hemoglobin $(\mathrm{OR}=0.64, p=0.04)$ and complement 3 (OR $=0.96, p=0.005)$ were associated with low levels of free 
Table 3. The univariate and multivariate logistic analysis for low free protein $\mathrm{S}(<50 \%)$ in SLE.

\begin{tabular}{lcccccccc}
\hline \multirow{2}{*}{ Variables } & \multicolumn{4}{c}{ Univariate } & \multicolumn{5}{c}{ Multivariate } \\
\cline { 2 - 9 } & OR & $95 \%$ CI for OR & $p$ value & OR & $95 \%$ CI for OR & $p$ value \\
\hline Age & 0.95 & 0.89 & 1.02 & 0.14 & 0.98 & 0.91 & 1.07 & 0.71 \\
\hline Hemoglobin & 0.6 & 0.42 & 0.84 & 0.003 & 0.64 & 0.42 & 0.99 & 0.04 \\
\hline Lymphocyte & 1.0 & 1.0 & 1.00 & 0.03 & 1.00 & 1.00 & 1.00 & 0.35 \\
\hline ESR & 1.03 & 1.0 & 1.03 & 0.04 & 1.01 & 0.98 & 1.04 & 0.67 \\
\hline Complement 3 & 0.96 & 0.93 & 0.98 & 0.001 & 0.96 & 0.93 & 0.99 & 0.005 \\
\hline Complement 4 & 0.91 & 0.85 & 0.98 & 0.007 & & & NA & \\
\hline Carotid IMT $>4.6 \mathrm{~mm}$ & 0.33 & 0.07 & 1.51 & 0.15 & 0.25 & 0.05 & 1.43 & 0.12 \\
\hline
\end{tabular}

SLE, systemic lupus erythematosus; ESR, erythrocyte sedimentation rate; IMT, intima media thickness; OR, odds ratio; CI, confidence interval; NA, not available.

protein S.

\section{Discussion}

Protein S has been known to interact with TAM receptors on apoptotic cells and enhance their clearance without further inflammatory reactions (van der Meer et al. 2014). Decreased levels of free protein S in SLE could affect the incomplete removal of debris and drive autoimmune responses, cumulating in autoantibody formation causing systemic inflammation (Munoz et al. 2008). Among 111 Korean patients with SLE, patients with low levels of free protein S had lower hemoglobin and lymphocyte count, higher ESR, and lower levels of complements compared to those with normal levels of free protein S. However, the cIMT and presence of carotid plaque were not different between them. Moreover, hemoglobin and complement 3 were associated with low levels of free protein $\mathrm{S}$ in patients with SLE.

The complement pathway can be activated to eliminate damaged cells and has many functions including opsonization, chemotaxis, cell activation, and the lysis of target cells. Complement components such as C3, C4 and C1q are useful markers, not only for patients with several infections, but also for patients with chronic self-reactive inflammation like SLE (Winberg et al. 2017; Margery-Muir et al. 2018). Complement depletion is a typical manifestation and also used as disease activity marker in SLE, and it has been found that it makes patients with SLE vulnerable to infection. In our study, the complements (C3 and C4) are lower in the patients with defective levels of free protein $\mathrm{S}$, especially C3 were found to be associated independently with the low levels of free protein S. A study showed the depletion of complements was correlated positively with protein $\mathrm{S}$ as one of various inflammatory parameters in sepsis (Lendak et al. 2018). This study could identify the correlation between free protein $\mathrm{S}$ and complement levels, which represents not only systemic inflammation clinically, but also the defects in clearance of apoptotic debris as major pathogenesis of SLE. In addition, the correlation between increased ESR and low levels plasma free protein $\mathrm{S}$ could be related with systemic inflammatory status in SLE. Such defect might contribute to one of pathogenesis of SLE, the process of unremoved cell debris and autoantibody production leading to unnecessary immune response.

Lymphopenia and hemolytic anemia are common hematologic manifestations and one of biomarkers for disease activity or prognosis of SLE (Mu et al. 2018). Hemoglobin levels are decreased through the complicated ways including hemolysis, iron deficiency or chronic inflammation, could represent disease status in chronic inflammatory disease. In this study, the hemoglobin levels were analyzed according to the level of plasma free protein S. The hemoglobin levels were lower in the patients having the low levels of free protein S. Similarly, the levels of free protein S were lower in SLE patients with active hematological involvement in previous data (Suh et al. 2010). Although the detailed mechanism needs to be investigated, defective levels of free protein S might lead to deterioration of hematologic system in patients with SLE.

Cardiovascular diseases such as stroke or myocardial infarction, develop earlier and more frequently in patients with SLE compared to the normal population (Esdaile et al. 2001; Roman et al. 2003). Many researches showed subclinical atherosclerosis represented by cIMT or carotid plaque was increased in patients with SLE compared to age and sex-matched healthy controls (de Leeuw et al. 2006; McMahon et al. 2014). In addition, the risk for CVD among patients with SLE was related to the disease-related features including disease activity and treatment patterns as well as the traditional risk factors (Jung et al. 2019). It has been reported that disease activity markers such as complement levels and SLEDAI, anti-phospholipid antibodies, nephritis, and CVD are related morbidity or mortality in SLE (Cacciapaglia et al. 2009; Jung et al. 2014). However, increased cIMT or the presences of plaque were not different between two groups divided by the levels of free protein $\mathrm{S}$ in this study. Low levels of free protein $\mathrm{S}$ might have little effect on subclinical atherosclerosis in Korean patients 
with SLE.

There were some limitations in this study. Sample size was relatively small to assess the relationships between several manifestations or laboratory findings and the defective levels of protein S. There was no definite difference in protein $\mathrm{S}$ according to severity or clinical characteristics of SLE except hemoglobin and complement 3. However, this is the first study to investigate relationship between a ligand of TAM receptors and subclinical atherosclerosis in patients with SLE. Abnormal levels of free protein S which are regarded as contributing an impaired clearance of apoptotic cells might have little effect on subclinical atherosclerosis in SLE.

In conclusion, the defective levels of plasma free protein $\mathrm{S}$ were independently associated with hemoglobin and complements levels, but not with subclinical atherosclerosis in Korean patients with SLE.

\section{Acknowledgments}

This research was supported by a grant of the Korea Health Technology R\&D Project through the Korea Health Industry Development Institute (KHIDI), funded by the Ministry of Health \& Welfare, Republic of Korea (grant number: HI16C0992).

\section{Conflict of Interest}

The authors declare no conflict of interest.

\section{References}

Anderson, H.A., Maylock, C.A., Williams, J.A., Paweletz, C.P., Shu, H. \& Shacter, E. (2003) Serum-derived protein S binds to phosphatidylserine and stimulates the phagocytosis of apoptotic cells. Nat. Immunol., 4, 87-91.

Bombardier, C., Gladman, D.D., Urowitz, M.B., Caron, D. \& Chang, C.H. (1992) Derivation of the SLEDAI. A disease activity index for lupus patients. The Committee on Prognosis Studies in SLE. Arthritis Rheum., 35, 630-640.

Cacciapaglia, F., Zardi, E.M., Coppolino, G., Buzzulini, F., Margiotta, D., Arcarese, L., Vadacca, M., Amoroso, A. \& Afeltra, A. (2009) Stiffness parameters, intima-media thickness and early atherosclerosis in systemic lupus erythematosus patients. Lupus, 18, 249-256.

de Leeuw, K., Freire, B., Smit, A.J., Bootsma, H., Kallenberg, C.G. \& Bijl, M. (2006) Traditional and non-traditional risk factors contribute to the development of accelerated atherosclerosis in patients with systemic lupus erythematosus. Lupus, 15, 675-682.

El Beshlawy, A., Alaraby, I., Abou Hussein, H., Abou-Elew, H.H. \& Mohamed Abdel Kader, M.S. (2010) Study of protein C, protein S, and antithrombin III in newborns with sepsis. Pediatr. Crit. Care Med., 11, 52-59.

Engesser, L., Broekmans, A.W., Briet, E., Brommer, E.J. \& Bertina, R.M. (1987) Hereditary protein S deficiency: clinical manifestations. Ann. Intern. Med., 106, 677-682.

Esdaile, J.M., Abrahamowicz, M., Grodzicky, T., Li, Y., Panaritis, C., du Berger, R., Cote, R., Grover, S.A., Fortin, P.R., Clarke, A.E. \& Senecal, J.L. (2001) Traditional Framingham risk factors fail to fully account for accelerated atherosclerosis in systemic lupus erythematosus. Arthritis Rheum., 44, 23312337.

Gheita, T.A., Bassyouni, I.H. \& Bassyouni, R.H. (2012) Plasma concentrations of growth arrest specific protein 6 and the soluble form of its tyrosine kinase receptor Axl in patients with systemic lupus erythematosus and Behcets disease. $J$. Clin. Immunol., 32, 1279-1286.

Gladman, D.D., Urowitz, M.B., Goldsmith, C.H., Fortin, P., Ginzler, E., Gordon, C., Hanly, J.G., Isenberg, D.A., Kalunian, K., Nived, O., Petri, M., Sanchez-Guerrero, J., Snaith, M. \& Sturfelt, G. (1997) The reliability of the Systemic Lupus International Collaborating Clinics/American College of Rheumatology Damage Index in patients with systemic lupus erythematosus. Arthritis Rheum., 40, 809-813.

Jung, J.Y., Kim, H.A., Lee, H.Y. \& Suh, C.H. (2019) Body mass index and glucocorticoid dose contribute to subclinical atherosclerosis in Korean patients with systemic lupus erythematosus: a prospective 4 year follow-up study. Int. J. Rheum. Dis., 22, 1410-1418.

Jung, J.Y., Koh, B.R., Bae, C.B., Kim, H.A. \& Suh, C.H. (2014) Carotid subclinical atherosclerosis is associated with disease activity but not vitamin D in Korean systemic lupus erythematosus. Lupus, 23, 1517-1522.

Kristoffersen, A.H., Petersen, P.H., Roraas, T. \& Sandberg, S. (2017) Estimates of within-subject biological variation of protein $\mathrm{C}$, antithrombin, protein $\mathrm{S}$ free, protein $\mathrm{S}$ activity, and activated protein $\mathrm{C}$ resistance in pregnant women. Clin. Chem., 63, 898-907.

Lendak, D., Mihajlovic, D., Mitic, G., Ubavic, M., NovakovMikic, A., Boban, J. \& Brkic, S. (2018) Complement component consumption in sepsis correlates better with hemostatic system parameters than with inflammatory biomarkers. Thromb. Res., 170, 126-132.

Levine, J.S., Subang, R., Setty, S., Cabrera, J., Laplante, P., Fritzler, M.J. \& Rauch, J. (2014) Phospholipid-binding proteins differ in their capacity to induce autoantibodies and murine systemic lupus erythematosus. Lupus, 23, 752-768.

Margery-Muir, A.A., Bundell, C., Wetherall, J.D., Whidborne, R., Martinez, P. \& Groth, D.M. (2018) Insights on the relationship between complement component C4 serum concentrations and C4 gene copy numbers in a Western Australian systemic lupus erythematosus cohort. Lupus, 27, 1687-1696.

Marlar, R.A. \& Gausman, J.N. (2011) Protein S abnormalities: a diagnostic nightmare. Am. J. Hematol., 86, 418-421.

McMahon, M., Skaggs, B.J., Grossman, J.M., Sahakian, L., Fitzgerald, J., Wong, W.K., Lourenco, E.V., Ragavendra, N., Charles-Schoeman, C., Gorn, A., Karpouzas, G.A., Taylor, M.B., Watson, K.E., Weisman, M.H., Wallace, D.J., et al. (2014) A panel of biomarkers is associated with increased risk of the presence and progression of atherosclerosis in women with systemic lupus erythematosus. Arthritis Rheumatol., 66, 130-139.

Mihajlovic, D., Brkic, S., Lendak, D., Novakov Mikic, A., Draskovic, B. \& Mitic, G. (2017) Endogenous thrombin potential as marker of procoagulant response that can be useful in early stage of sepsis. Blood Coagul. Fibrinolysis, 28, 460-467.

Mu, L., Hao, Y., Fan, Y., Huang, H., Yang, X., Xie, A., Zhang, X., Ji, L., Geng, Y. \& Zhang, Z. (2018) Mortality and prognostic factors in Chinese patients with systemic lupus erythematosus. Lupus, 27, 1742-1752.

Munoz, L.E., van Bavel, C., Franz, S., Berden, J., Herrmann, M. \& van der Vlag, J. (2008) Apoptosis in the pathogenesis of systemic lupus erythematosus. Lupus, 17, 371-375.

Naqvi, T.Z. \& Lee, M.S. (2014) Carotid intima-media thickness and plaque in cardiovascular risk assessment. JACC Cardiovasc. Imaging, 7, 1025-1038.

Petri, M., Orbai, A.M., Alarcon, G.S., Gordon, C., Merrill, J.T., Fortin, P.R., Bruce, I.N., Isenberg, D., Wallace, D.J., Nived, O., Sturfelt, G., Ramsey-Goldman, R., Bae, S.C., Hanly, J.G., Sanchez-Guerrero, J., et al. (2012) Derivation and validation of the Systemic Lupus International Collaborating Clinics classification criteria for systemic lupus erythematosus. Arthritis Rheum., 64, 2677-2686. 
Pintao, M.C., Ribeiro, D.D., Bezemer, I.D., Garcia, A.A., de Visser, M.C., Doggen, C.J., Lijfering, W.M., Reitsma, P.H. \& Rosendaal, F.R. (2013) Protein S levels and the risk of venous thrombosis: results from the MEGA case-control study. Blood, 122, 3210-3219.

Recarte-Pelz, P., Tassies, D., Espinosa, G., Hurtado, B., Sala, N., Cervera, R., Reverter, J.C. \& de Frutos, P.G. (2013) Vitamin $\mathrm{K}$-dependent proteins GAS6 and protein S and TAM receptors in patients of systemic lupus erythematosus: correlation with common genetic variants and disease activity. Arthritis Res. Ther, 15, R41.

Roman, M.J., Shanker, B.A., Davis, A., Lockshin, M.D., Sammaritano, L., Simantov, R., Crow, M.K., Schwartz, J.E., Paget, S.A., Devereux, R.B. \& Salmon, J.E. (2003) Prevalence and correlates of accelerated atherosclerosis in systemic lupus erythematosus. N. Engl. J. Med., 349, 2399-2406.

Rothlin, C.V. \& Lemke, G. (2010) TAM receptor signaling and autoimmune disease. Curr. Opin. Immunol., 22, 740-746.

Suh, C.H., Hilliard, B., Li, S., Merrill, J.T. \& Cohen, P.L. (2010) TAM receptor ligands in lupus: protein S but not Gas6 levels reflect disease activity in systemic lupus erythematosus. Arthritis Res. Ther., 12, R146.

Suleiman, L., Negrier, C. \& Boukerche, H. (2013) Protein S: a multifunctional anticoagulant vitamin K-dependent protein at the crossroads of coagulation, inflammation, angiogenesis, and cancer. Crit. Rev. Oncol. Hematol., 88, 637-654.

Tabib, Y., Jaber, N.S., Nassar, M., Capucha, T., Mizraji, G., Nir, T., Koren, N., Aizenbud, I., Maimon, A., Eli-Berchoer, L.,
Wilensky, A., Burstyn-Cohen, T. \& Hovav, A.H. (2018) Cellintrinsic regulation of murine epidermal Langerhans cells by protein S. Proc. Natl. Acad. Sci. USA, 115, E5736-E5745.

van der Meer, J.H., van der Poll, T. \& van't Veer, C. (2014) TAM receptors, Gas6, and protein S: roles in inflammation and hemostasis. Blood, 123, 2460-2469.

Winberg, L.K., Nielsen, C.H. \& Jacobsen, S. (2017) Surface complement C3 fragments and cellular binding of microparticles in patients with SLE. Lupus Sci. Med., 4, e000193.

Wu, C.S., Hu, C.Y., Tsai, H.F., Chyuan, I.T., Chan, C.J., Chang, S.K. \& Hsu, P.N. (2014) Elevated serum level of growth arrest-specific protein 6 (Gas6) in systemic lupus erythematosus patients is associated with nephritis and cutaneous vasculitis. Rheumatol. Int., 34, 625-629.

Wu, J., Ekman, C., Jonsen, A., Sturfelt, G., Bengtsson, A.A., Gottsater, A., Lindblad, B., Lindqvist, E., Saxne, T. \& Dahlback, B. (2011) Increased plasma levels of the soluble Mer tyrosine kinase receptor in systemic lupus erythematosus relate to disease activity and nephritis. Arthritis Res. Ther., 13, R62.

Zhu, H., Sun, X., Zhu, L., Hu, F., Shi, L., Fan, C., Li, Z. \& Su, Y. (2014) Different expression patterns and clinical significance of $\mathrm{mAxl}$ and $\mathrm{sAxl}$ in systemic lupus erythematosus. Lupus, 23, 624-634.

Zizzo, G., Guerrieri, J., Dittman, L.M., Merrill, J.T. \& Cohen, P.L. (2013) Circulating levels of soluble MER in lupus reflect M2c activation of monocytes/macrophages, autoantibody specificities and disease activity. Arthritis Res. Ther, 15, R212. 